\title{
Serebral palsili çocuklarda rehabilitasyon planı ve takım yaklaşımı
}

\author{
Rehabilitation plan and team approach in children with \\ cerebral palsy
}

\author{
Mintaze Kerem Günel
}

Hacettepe Üniversitesi Sağlık Bilimleri Fakültesi, Fizyoterapi ve Rehabilitasyon Bölümü, Serebral Palsi ve Pediatrik Rehabilitasyon Ünitesi, Ankara

\begin{abstract}
Serebral palsi (SP) terimi, motor bozukluğu olan ve bununla ilgili hizmet gereksinimi duyan çocukları tanımlar. SP'nin erken teşhisi zordur, çünkü nörolojik işaretlerin gelişmesi zaman alır ve özellikle prematüre doğan çocuklarda geçici olabilir. Ülkemizde ise bu oran 1000 canlı doğum başına 4,4 oranındadır. SP kayıt sistemleri, toplumda görülme oranını tahmin etmek için tüm dünyada geliştirilmektedir. SP kayıt sistemleri, SP'li çocukların özelliklerinin, görülme oranının, eğilimlerinin takip edilmesi ve hizmetlerin planlanması için çok değerlidir. Eşlik eden problemlerin dikkatli bir şekilde tanımlanması ve SP'li çocuğun etkilenim şiddetinin oranlanması önemlidir. SP'nin klinik tipleri kas tonusu özelliklerine ya da diğer nörolojik ve fonksiyonel kapasite değerlendirme bulgularına göre iyi tanımlanmalıdır. Tedavi için, farklı teorik prensiplere dayanan ve farklı teknik ve yöntemler kullanan çok çeşitli terapi yaklaşımları bulunmaktadır. Bu farklı yaklaşımların etkinliğine dair az miktarda belgelenmiş bilimsel kanıt olması, ek ve birbirine karşıt terapi yaklaşımlarının varlığına yol açmaktadır. Terapi uygulayan kişiler araştırmacı, kolaylaştırıcı ve aileye öneri veren kişiler olmalıdır. Normal ve normal olmayan hareketler hakkında olduğu kadar piskolojik ve kompansatuvar davranış çeşitliliği hakkında da bilgi sahibi olmalıdır. SP tedavi, bakım ve rehabilitasyon sürecinde görev alan multidisipliner ekip, özürün şiddetine bağlı olarak, otonomi olan temel hedefi başarmak için birlikte çalışır; SP'yi tedavi etmeye çalışmaktan öte fonksiyonel kısıtlılıkları "yönetir", becerileri geliştirir ve çocuğun aile, okul ve iş yerindeki entegrasyonunu cesaretlendirir. SP, yaşam boyu süren bir durumdur. SP'li yetişkinler için mevcut sağlık bakım hizmetlerinde, en iyi uygulama klinik yönergelerinin geliştirilmesi ve uygulanması için kanıta dayalı bilgilere ihtiyaç vardır.
\end{abstract}

Anahtar sözcülkler: serebral palsi; rehabilitasyon; erken tanı; multidisipliner yaklaşım; terapi
Cerebral palsy (CP) term identify children with motor impairment who need services related to it. Early diagnosis of CP is difficult because the development of neurological signs takes time and may be temporary, especially in premature children. In our country this rate is 4.4 per thousand live births. Recording systems are developed all over the world to estimate the rate of CP in society. CP recording systems are very valuable for tracking the characteristics, incidence and trends of children with SP and for planning services. It is important that the accompanying problems are described carefully and that the severity of the impact on the child with CP is proportionate. Clinical types of SP should be well defined according to muscle tone characteristics or other neurological and functional capacity assessment findings. For treatment; there are a variety of therapeutic approaches based on different theoretical principles, and using different techniques and methods. The small amount of documented evidence of the effectiveness of these different approaches leads to the existence of additional and contradictory therapy approaches. The practitioners should be researchers, facilitators and proposers to the family. They should be informed about psychological and compensatory behavior as well as normal and abnormal movements of the child. The multidisciplinary team involved in the CP treatment, care and rehabilitation process "manages" the functional limitations beyond trying to treat co-operative $\mathrm{CP}$ to achieve the autonomous primary goal, depending on the severity of the problem, and improves skills and encourages integration in the child's family, school and workplace. CP is a lifelong situation. For health care services for adults with $C P$, evidence-based information is needed to develop and implement best practice of clinical guidelines.

Key words: cerebral palsy; rehabilitation; early diagnosis; multidisciplinary approach; therapy

- İletişim adresi: Prof. Dr. Mintaze Kerem Günel, Hacettepe Üniversitesi Sağlık Bilimleri Fakültesi, Fizyoterapi ve Rehabilitasyon Bölümü, Ankara Tel: 0312 - 3052525 / 131 e-posta: mintaze@hacettepe.edu.tr

- Geliș tarihi: 1 Ekim $2018 \quad$ Kabul tarihi: 1 Ekim 2018 
erebral Palsi (SP) terimi; spesifik bir hastalığın varlığını tanımlamaktan öte, farklı şiddette ve benzer gelişimsel problemleri olan bir grup hastalığı tanımlar. Uluslararası bir panelde yapılan genel bir tanıma göre SP şu şekilde tanımlanmışırı: "Gelişmekte olan beyinde meydana gelen ilerleyici olmayan bir takım bozuklukların neden olduğu postüral ve hareket bozukluklarııın aktivite limitasyonlarına yol açtığı bir grup kalıc hastalıktır'. SP'nin motor bozukluklarına ayrıca duyu bozuklukları, kognitif bozukluklar, algısal problemler, iletişim ve davranışsal problemlerin yanı sıra epilepsi ve ikincil kas iskelet sistemi problemleri eşlik etmektedir. ${ }^{[1]}$

SP çocukluk çağının en yaygın motor bozukluklarından biridir. Toplumsal kayıtlara göre SP prevalansı genel olarak 1000 canlı doğum başına $1,5-2,5$ oranında görülmektedir. Ülkemizde ise bu oran 1000 canlı doğum başına 4,4 oranındadır. ${ }^{[2]} \mathrm{SP}$ ömür boyu süren ve fiziksel olduğu kadar çoğunlukla duyu, bilişsel, psikolojik ve sosyal uyum problemlerini bir arada taşıyan ve fonksiyonel yetersizlik yaratan bir tablodur; oluşan engel durumu yaşla birlikte artı̧ gösterir ve yaşlanma nispetten daha erken başlar. Bakım süreci ve rehabilitasyon yaklaşımları, teşhisin ilk konulduğu yaş, hatta SP riski taşınılabilecek bebeklik ve yetişkinlik dönemlerini kapsamalıdır.

Neredeyse tüm SP'li çocukların normal yaşam beklentisi vardır, \%5-10 arası bir oranda çocukluk döneminde ölüm gerçekleşebilir. Şiddetli fiziksel bozukluğa epilepsi ve entellektüel problemlerin eşlik ettiği çocuklarda erken mortalite riski yüksek olmaktadır. ${ }^{[3]}$ Bu nedenle, uzun dönem prognoza daha az dikkat gösterilmesi dikkat çekici bir durumdur. Uzun dönem prognozdan elde edilen bilgiler, sadece ebeveynlere danışmanlık yapılmasında değil, aynı zamanda terapide ve bebeklikteki terapi kavramları açısından da kullanılabilir.

Toplam SP popülasyonunun yaklaşık \%60'ında ambulasyon bağımsız olarak başarilır (\%35,5 oranında özür seviyesi, I; \%24,5 oranında özür seviyesi, II); yaklaşı \%10 oranında yardımlı ambulasyon mevcuttur (\%10,7 oranında özür seviyesi, III); yaklaşık \%30 oranında ise tekerlekli sandalye ile mobilizasyon sağlanır (\%12,2 oranında özür seviyesi, IV). Geriye kalan \%14,1 oranında ise özür seviyesi $V$ olup ambulasyon sağlanamamaktadır. SP'ye en az fiziksel engel kadar önemli ve sonuçları etkileyen başka bir takım bozukluklar da eşlik eder: Ağrı (3/4'ünde), entellektüel bozukluklar ( $1 / 2$ 'sinde), yürüyememe (1/3'ünde), kalça çıkığı (1/4'ünde), konuşma problemleri (1/4'ünde), epilepsi (1/4'ünde), davranış bozuklukları ( $1 / 4$ 'ünde), mesane inkontinansı (1/4'ünde), uyku bozuklukları ( $1 / 5^{\prime}$ 'inde), görme problemleri ( $1 / 10^{\prime}$ unda) ve işitme kaybı ( $1 / 25^{\prime}$ inde). Tüm bu eşlik eden sorunlar çocuğun hem bağımsızlı̆̆ını hem de bakım ve rehabilitasyon süreçlerini etkiler. ${ }^{[4]}$

Zihinsel yetersizlikleri olmayan SP'li çocuklar; genellikle günlük aktivitelerini, mobilite ve iletişimlerini kendi kendine yapabilir. Ancak, çocukların aileleri, çocukların \%70'inde günlük hayatla ilgili bazı sorunlar olduğunu bildirmektedirler. Bu sorunların; öz bakım (\%59), oyun oynama (\%37) ve okul aktiviteleri (\%52) gibi faaliyetlerde meydana geldiği bildirilmiştir. ${ }^{[5]}$ SP'li çocuklar, sosyal entegrasyon ile ilgili olarak ciddi güçlükler yaşar. Bu durum, spor faaliyetleri gibi uygun boş zaman aktiviteleri için de geçerlidir. ${ }^{[6]}$

SP'li çocuklarda problemlerin yönetimi çocuktan çocuğa değişkenlik gösterir. Bazı çocuklarda problemler doğumdan hemen sonra değişen derecelerde kendini gösterirken bazılarında ise problem erken çocukluk döneminde ortaya çıkar. Çeşitli nedenlerle meydana gelen beyin hasarı, çocuk büyüdükçe çeşitli semptomlarla kendini göstermeye başlar. Bundan ötürü, SP alanında çalışan tüm sağlık profesyonelleri kendi uzmanlık alanlarına uygun değerlendirme yöntemleri ile çocuğu kapsamlı bir şekilde değerlendirmelidir.

SP'li çocuklarda rehabilitasyon süreci oldukça karmaşık ve çok faktörlü bir denklem gibidir. İstenilen amaca ulaşlabilmesi birçok disiplinin bir arada çalışmasına bağılıdır. Bu nedenle, günümüzde rehabilitasyon yaklaşımları ekip yaklaşımı kavramı içinde ele alınmaktadır ve rehabilitasyonun başarısı için bu durum bir zorunluluktur. Çocuğa ve aileye ait özelliklerin, engel yaratan ya da yaratabilecek durumların her çocukta farklı tablolar oluşturması nedeniyle, ilgili disiplinlerin rehabilitasyondaki rolleri de değişiklik göstermektedir. Tedavi planına veya bu kapsamda yer alan terapi planlarına, kesinlik kazanmış bir tanıdan sonra yapılan kapsamlı bir değerlendirmeden sonra karar verilir. ${ }^{[7]}$ Öncelikle, ailenin beklentileri ve çocuğun ihtiyaçları ile birlikte aile ve çocuğun merkezde olması; çocukların çok yönlü terapi ihtiyaçlarının bütüncül değerlendirilmesi gerekmektedir. Bu değerlendirmeler aynı anda tüm hekim, terapist ve uzmanların bir arada olduğu bir ortamda, aile ve çocuğun doğal ortamda gözlemlenmesiyle yapılmalı ve profesyoneller de birbirlerine görüşlerini aynı ortamda iletmelidir. Bu şekliyle, çocuk ve aile için en etkili terapi ve bakım programlarının belirlenmesi mümkün olabilir.

SP'li çocuklarda "rehabilitasyon" yaklaşımları, doğum öncesi, doğumda ya da doğum sonrası nedenlerle oluşabilen fiziksel, duyu-algı, bilişsel ve sosyal problemlerin çocukta yarattığı problemlere profesyonel ve multidisipliner ekip yaklaşımını gerektiren bir olgudur.

Günümüzde SP'ye müdahaleler vücuttaki işlev ve yapı bozukluklarını belirlemeyi, aktivitedeki kısıtlanmaları 
en aza indirmeyi, fonksiyonel becerileri geliştirmeyi, çocuğun yaşına uygun ortamlarda katılımını desteklemeyi amaçlar. Erken yaşlarda, bütün gelişim alanlarının geliştirilmesine odaklanılır. Rehabilitasyon uygulamalarında hedefe yönelik terapiler; davranışsal bir hedef etrafinda organize olmuş hareketler bütünüdür. Fonksiyonel hedef, hareket stratejilerini geliştirmek için kullanılmakta, hareketin oluşması da çevre tarafından zenginleştirilmektedir. ${ }^{[8]}$

Terapilerin ve bakım sistemlerinin uluslararası fonksiyon sınıflaması (ICF) içeriklerine uygun şekilde, aktivite ve katılımın gerçekleştirilebilmesi için fonksiyonel nitelikte olması ön planda tutulmaktadır. Hedefe yönelik nöromotor tedavi, çocuklarda ICF'in "Aktiviteler ve Katılım" alanına uygun fonksiyonel nitelikte bir tedavi uygulamasıdır. SP'li çocuklar için rehabilitasyon yöntemleri ICF çerçevesinde ele alınmaktadır. ${ }^{[9]}$

Ekip elemanlarının kendi alanlarıyla ilgili çocukları ayrıntılı değerlendirmelerinin yanı sıra tüm ekibin ortak dil oluşturması, beraber çalışabilmenin ilk gerekliliklerinden sayılabilir. Öncelikle SP'nin sınıflandırmasında ekibin ortak dil kullanması çok önem taşımaktadır. Sınıflandırmalar etkilenen vücut kısımlarına (topografik), motor bulgular doğrultusundaki klinik tipe, yol açan patolojiye ve etkilenim şiddetine göre çeşitli başlıklar altında incelenebilir. Patoloji ve etiyoloji pek çok olguda belirsiz olduğu için, günümüzde en sık kullanılan sistem, klinik özelliklere göre yapılan SCPE (Surveillance Cerebral Palsy Europe)'nin sınıflandırma sistemidir. SCPE sınıflandırma sistemi, uluslararası bir dil yaratma yolunda ilerlemektedir. SCPE tarafindan benimsenen sistem SP'yi, spastik, bilateral spastik (kuadriplejik/diplejik), unilateral spastik (hemipleji), diskinetik, distonik ve koreoatetoid ve ataksik olarak sınıflandırmaktadır. ${ }^{[10]}$

Diğer bir önemli kavram, ekip arasında SP'li çocukların tedavi, terapi ve bakım stratejileri ve yöntemlerinin belirlenmesinde önem taşıyan beş seviyeli sınıflama sistemleridir. Kaba motor sınıflama sistemi (GMFCS), SP'li çocuğun oturma ve yürümede kendi kendine yapabildiği fonksiyonel becerileri ve aynı zamanda yürüteç ve tekerlekli sandalye ihtiyacını değerlendiren bir sistemdir. Bu sistem, SP'li çocuğun yaşa özgü özür seviyesini ve ayrıca bağımsız ambulasyon için gerek duyduğu adaptif cihazı belirlemede referans alınabilen bir sınıflamadır. El Becerileri Sınıflandırma Sistemi (MACS) SP'li çocukların günlük aktivitelerde objeleri nasıl kavradıklarını belirler. Beceri seviyesi ile ters orantılı olarak artan toplam beş seviyeden oluşmakla birlikte her bir seviye çocukların objeleri kendiliğinden kavrama becerilerine denk gelir. İletişim Fonksiyonlarını Sınıflandırma Sistemi (CFCS), SP'li bir bireyin günlük yaşamda iletişim fonksiyonlarını beş seviyeli bir ölçekte değerlendirir. Dünya Sağlık Örgütü (DSÖ)'nün tanımladığı Sağlığın, Engelliliğin ve İşlevselliğin Uluslararası Sınıflandırma (ICF-CY) perspektifi aktivite ve katılıma yoğunlaşır. Yeme ve İçme Becerileri Sınıflandırma Sistemi (EDACS), SP'li çocuklarda yeme ve içme becerilerini beş seviyeli bir sınıflandırma sisteminde değerlendiren ölçektir. Bu sınıflandırma sistemi GMFCS, MACS ve CFCS gibi sınıflandırma sistemlerinin birer analoğu ve tamamlayıcısıdır. ${ }^{[11-14]}$

SP'li çocukların motor ve duyusal bozukluklarının tedavisinde fizyoterapistler kaba motor becerilere ve fonksiyonel mobiliteye odaklanır. Pozisyonlama, oturma, destekleyici aletler veya ortez yardımıyla ya da yardımsız yürüme, tekerlekli sandalye kullanımı için gerekli fonksiyonel durumun sağlanması ve transferler, ikincil problemlerin önlenmesi fizyoterapistin üzerinde çalıştığı ana alanlardandır. Fizyoterapist, fizyoterapi programını ve ailenin evde uygulayacağı ev programını planlar ve uygular, çocuğu okul ortamına hazırlar ve gerekli ekipman ve ortezi önerir. Aynı zamanda; yemek yeme, giyinme, tuvalet, banyo yapma gibi temel günlük aktiviteler için gerekli olan görsel-motor ve duyusal becerilere odaklanır. Fizyoterapi yaklaşımları ayrıca, okulla ilişkili beceriler kazandırılması ve günlük yaşamı zorlaştıran eksiklikleri telafi etmeye yardımcı olacak stratejileri de içerir. ${ }^{[15]}$

Fizyoterapi uygulamaları için etkin değerlendirme gereklidir. Bir çocuğun değerlendirilmesinde, "Fizyoterapi neden gereklidir?", "Etkin nörofizyolojik ve biyomekanik mekanizmalar nelerdir?", "Eşlik eden sorunlar durumu nasıl etkiliyor?", "Çocuğun ve ailenin terapiyi etkileyecek genel yapısı nelerdir?” gibi sorulara yanıt aranmalıdır. Motor değerlendirme, kas tonusundaki değişimleri, kasların kontraksiyon kapasitesini, istem dışı ekstremite ve gövde hareketlerini, gövde ve ekstremitelerin stabilitesini, düzeltme ve denge tepkilerini, oturma dengesini, üst ekstremite ve el fonksiyonlarını, duyusal-algısal sorunları, konuşma ve dil fonksiyonu ve beslenme durumunu içermelidir. Ayrıca, ortez, mobilizasyon ve diğer adaptasyon cihazları, çocuğun genel sağlık durumu ve ailenin sosyokültürel ve ekonomik şartları da değerlendirilmelidir. Gerçekçi hedefler tanımlanmalı ve tedavi sürecindeki herhangi bir değişiklik tedavi ekibinin diğer üyeleri, aile ve çocukla birlikte değerlendirilmelidir. SP alanında uygulanan fizyoterapi yaklaşımlarını gruplarsak; nörofizyolojik temelleri ayarlamak için yaklaşımlar, motor öğrenme prensibine dayanan yaklaşımlar, spesifik semptomlarını tedavi eden yaklaşımlar (gelişimsel, ortopedik ve nörolojik) öncesi ve sonrası fizyoterapi uygulamalar olarak özetleyebiliriz.

Uygulamalar için gerekli şartlara baktığımızda ise; bağımsız ve fonksiyonel aktiviteler için motivasyon, 
istenilen hareket ya da aktivitenin örneklenmesi, ayrıca özel gösterim ve taklit için motivasyon, duyular, hem motivasyonu hem de tedavideki ve günlük yaşamdaki uyumu arttırmak için yeterli ve makul kısa ve uzun dönem hedeflerin seçilmesi, öğrenmeyi desteklemek için küçük başarılarda bile pozitif geri bildirim, öğrenme içeriklerinin depolanmasını arttırmak ve sağlamlaştırmak için tekrarların önemi göz önünde bulundurulmalıdır. ${ }^{[16]}$

Günümüzde terapi etkileri ve kazanılan ilerlemenin normal psikomotor gelişim ile aynı nörofizyolojik temellere dayanmakta olduğu varsayılmaktadır. Kısıtlı ve spesifik olsalar bile (ayak-ayak bileği ortezi gibi) terapötik müdahalelerin, duyusal zinciri değiştirdikleri için tüm organizma üzerinde etkileri vardır. Eğer bunlar hedefe yönelik fonksiyon ve becerilerde gelişmeye neden olursa tekrarlı olarak kullanılır ve böylece uzun süreli hafizada depolanır. Burada, santral sinir sisteminin kendi kendine organizasyonu ve plastisitesinin beceri ve olasılıkları varsayılmıştır. Terapi için; farklı teorik prensiplere dayanan ve farklı teknik ve yöntemler kullanan çok çeşitli terapi yaklaşımları bulunmaktadır. Bu farklı yaklaşımların etkinliğine dair az miktarda belgelenmiş bilimsel kanıt olması ek ve birbirine karşıt fizyoterapi yaklaşımların varlığına yol açmaktadır. ${ }^{[17]}$

Fizyoterapi ve rehabilitasyon yaklaşımlarının hedefleri; normal gelişimi, özellikle motor gelişimi desteklemek, kas tonusunu geliştirmek, düzeltme reaksiyonlarının gelişimini arttırmak, görsel ve işitsel reaksiyonları geliştirmek, kas-iskelet sistemi deformitelerini engellemek, duyusal ve motor deneyimleri normalleştirmek, aile eğitimi vermek, nöromotor değişiklikleri düzenli kontrollerle izlemek olarak sıralanabilir. Uygun fizyoterapi yaklaşımının belirlenmesinde kronolojik yaş, fizyoterapiye başlama yaşı, anormal reflekslerin varlığı ve şiddeti, postüral reaksiyonların yetersizliği, kas tonusu problemleri, birlikte görülen bilişsel sorunlar, işitme-görme-duyu-algı sorunları, genel sağlık durumu, aile desteği ve ekonomik durum da önemli olmaktadır.

Gelişimsel terapi uygulayan fizyoterapist, ilk olarak çocuğun mevcut performansını gözlemler, analiz eder ve yorumlar. Ardından çocuğun potansiyel değerlendirme sonuçları doğrultusunda ve var olan kısıtlanmalarına göre maksimal bağımsızlık düzeyine ulaşmasını sağlamayı amaçlar. Uygulamanın yoğunluğu konusunda kesin kurallar yoktur. Ancak, ortopedik girişimler ve nöro-cerrahiler sonrasında, çocuğun hareket biyomekaniğini etkileyebilecek büyüme ataklarında ya da spesifik bir görevin başarılma sürecinde yoğunlaştırılmış terapi kritik önem taşımaktadır. Böylelikle yeni beceri edinimi için motivasyon sağlanabilir.
SP'li çocuklarda, büyük bir ekibin beraber yaklaşmasını gerektiren motor bozuklukların nedenleri; gelişme geriliği, anormal kas tonusu, kas zayıflığı, postür kontrolü yetersizliği, duyusal, davranışsal ve ortopedik sorunlar, anormal hareket şekilleri ve refleks hareketleri, asimetri ve deformitelerdir. Bir çocuğun motor gelişimi evrelerinde kazanması gereken fonksiyonlar, lezyonun derecesine bağlı olarak gecikmekte ve normal gelişim sürecinde bastırılmış olması gereken ilkel reflekslerin varlığı düzeltme ve denge tepkilerinin gelişimini engellemektedir. ${ }^{[18]}$

SP'li çocukların değerlendirilmesinde, tüm ekibin ortak olarak kullanabileceği ve yapılan ekip yaklaşımın gerekliliğini ve etkinliğini değerlendirebileceği değerlendirme ölçekleri-testleri-anketleri de çok önemlidir. Bunları kısaca gözden geçirecek olursak; kaba motor fonksiyon ölçeği (GMFM), yürüme fonksiyonlarının değerlendirilmesi için kullanılan, Edinburgh Gözlemsel Yürüme Skoru, Modified Physician Rating Scale (PRS), Rivermead Gözlemsel Yürüme Analizi Formu, üst ekstremite değerlendirme araçlarından; Abilhand-Kids Anketi, Çocukların El Kullanım Deneyim Anketi (CHEQ 2.0 Versiyon), ACTIVLIM-Etkinlik Kısıtlama Anketi, Upper Extremity Physician's Rating Scale, Üst Ekstremite Beceri Kalitesi (QUEST), günlük yaşam aktivitelerini değerlendiren araçlardan; Fonksiyonel Bağımsızlık Ölçütü (Wee FIM), Pediatrik özürlülük değerlendirme envanteri (PEDI), yaşam kalitesini değerlendiren araçlardan; Quality of Life Questionnaire for Children (CP QOL-Child, Pediatric Quality of Life Inventory (PedsQL; Çocukluk Çağı Sağlık Değerlendirme Anketi (CHAQ) sayılabilir. ${ }^{[19-24]}$

$S P$ riski taşıyan bebeklerde, özellikle yaşamın ilk bir yılında; gelişimsel sorunların erken saptanması, yaşamın ilk yılı boyunca erken müdahale, destek terapiler ve rehabilitasyon yaklaşımları için çok önemlidir. Erken dönemde riskli bebeklerin desteklenmesi ve uygun hizmet verilmesi için erken teşhis ve sınıflandırılma önemlidir. Uygun müdahalenin planlanması, değişikliklerin takip edilmesi, çevrenin, verilen destek tedavilerinin ve rehabilitasyon yaklaşımlarının değerlendirilmesi habilitasyonun ana unsurunu oluşturur.

Prematüre bebeklerin yaşam şansları günümüzdeki yoğun bakım koşul ve olanakları ile artmış olduğundan, bunlar gelişimsel açıdan risk taşıyan en büyük grubu oluşturmaktadır. Bu çocuklar; motor sorunlar, hareket koordinasyonunda bozukluk, bilişsel bozukluk, dikkat eksikliği, öğrenme güçlüğü gibi nörogelişimsel bozukluklar ve \%5-15 oranında da SP riski taşımaktadırlar. Riskli bebeklerin erken dönemde tanınarak, nörogelişimsel değerlendirme ile belirlenen bütüncül ve aile odaklı fizyoterapi ve rehabilitasyon yöntemleri ile izlenmeleri, nöral plastisiteyi destekleyecek ve olası nörogelişimsel sorunların çözümlenmesine katkıda 
bulunacaktır. Bu alanda çalışacak fizyoterapistlerin ve sağlık profesyonellerinin, prematüre bebeklerin değerlendirilmesi ve terapisine ilişkin eğitim ve tecrübelerinin geliştirmesi gereklidir. Nörolojik gelişimi destekleyici, uzman fizyoterapistler elinde şekillenen, hedefe yönelik, aile odaklı fizyoterapi uygulamaları nöral plastisiteyi desteklemektedir. Prematüre bebekler için gerektiğinde uygulanan "habilitasyon" yaklaşımlarında temel amacı, beyin plastisitesinden hızlı öğrenme ve uyum yeteneğini kullanarak, normal fonksiyonel hareketlerin kazandırılması ve normal duyu girdisinin verilmesi; çocuğun fizyolojik ve anatomik yetersizlikleri ve çevresel sınırıııkları içerisinde fiziksel, bilişsel, psikolojik ve sosyal açılardan mümkün olabilen en bağımsız seviyelere ulaştırılması olarak tanımlayabiliriz. ${ }^{25,26]}$

SP'li çocuklarda, hayatlarının ilerleyen dönemlerinde genel olarak kas iskelet, postüral kontrol, motor kontrol, motor öğrenme, yürüme, denge ve koordinasyon problemleri görülür. Bu problemlere duyu-algı-motor bozukluklar, emosyonel, bilişsel, psikososyal vb. sorunlar da yaygın biçimde eşlik eder. Tüm bu problem karmaşıklıklarını göz önünde bulundurduğumuzda, bu alandaki bakım ve tedavi sürecinin zorlukları en göze çarpan bir sorun olarak karşımıza çıkmaktadır. Bundan ötürü, SP'li çocukların bakım ve rehabilitasyon süreci multidisipliner bir çalışma gerektirir.

SP'li çocuklarda, fiziksel, duyusal, kognitif ve psikolojik problemlerin yol açtı̆̆ı engel durumunun multifaktöryel olması nedeniyle, bu sürecin sistematik biçimde ve kendi alanlarında disipline olmuş uzmanlarca yürütülmesinde yarar vardır. SP alanında çalışan sağlık profesyonelleri, almış oldukları eğitimler doğrultusunda SP'li bireylerin problemlerini bütüncül bir şekilde ele almalıdırlar. Problemlerin saptanması kadar, çözümlerini sağlayacak düzeyde bilgi ve becerilerinin de olması gerekir. Gerçekçi hedefler belirlemenin yanında aynı zamanda geniş yelpazede literatür bilgilerinin olması gerekir. Çocuğun sürekli pasif bırakıldığı terapötik yaklaşımları uygulamaktan ziyade, daha aktif olduğu ve hareketin aktivite içinde öğrenildiği terapötik yaklaşımlar ön planda tutulmalıdır. Yararlı olmayacak yaklaşımlardan uzak durmanın yanında, kanıta dayalı yaklaşımlar çocuğun ihtiyacına göre belirlenmeli ve uygulanmalıdır. SP rehabilitasyonunda kullanılan uygulamaları genel olarak şu şekilde sınıflandırılabiliriz:

1. Çocuğun aktif olduğu yaklaşımlar: Bu tür uygulamalarda çocuk aktif olarak görev alır ve gerçek zamanIı aktiviteleri bizzat kendisi tecrübe eder. Bu amaçla çocuk öğrenmek istediği hareketleri günlük yaşam aktivitelerinde kullanılan aktivitelerle pekiştirir. Bu tip yaklaşımlar nöroplastisiteye yol açan kanıta dayalı nörobilim prensiplerini temel alırlar. Çocuğun aktif olduğu yaklaşımlar şu özellikleri içerir: hedefe yönelik olma, göreve özgü uygulamalar, yüksek dozda tekrar, kullanmaya bağlı plastisite, deneyimlemeye bağlı plastisite ve ögrenmeye bağlı plastisitenin aktifleştirilme çabaları.

2. Kompansasyon ve çevresel adaptasyonları içeren yaklaşımlar: Bu tür yaklaşımlar toplumsal alanlarda bir takım düzenlemelerin yapıldığı yaklaşımlardır. Yani çocuğu değiştirmek yerine çevreyi değiştirmeyi esas alır. Bu uygulamalar çevresel ve aktivite modifikasyonlarını içerir veya çeşitli spesifik ekipmanlar çocuğun engel durumuna göre uyarlanarak çocuğun optimal bağımsızlığı sağlanmaya çalışılır.

3. Sağlık ve ikincil önleme yaklaşımları: Bu tür uygulamalar SP'li çocukta fonksiyonel yetersizlik, aktivite ve katılımda engele neden olan temel bozukluklar kadar etkili olan sağlık ve eşlik eden problemleri önlemeye yönelik uygulamaları içerir (örneğin nöbet veya epilepsi kontrollü). Diğer bir amaç ise SP'nin doğal seyrini düzenlemek veya olası problemleri azaltmaktır. ${ }^{[27,28]}$

En çok tercih edilen terapi yaklaşımlarını, Bobath (Nörogelişimsel Tedavi), kuvvetlendirme egzersizleri, denge egzersizleri, ortez kullanımı, spastisite yönetimi, kısıtlayıcı zorunlu hareket tedavisi (CIMT), her iki elin yoğun kullanım ve koordinasyonunu amaçlayan tedavi (HABIT), yardımcı cihaz ve ekipman kullanımı, hayvan destekli terapi, hippoterapi, su içi egzersiz uygulamaları olarak özetlemek mümkün olabilir. ${ }^{[29-32]}$

Terapilerde, günümüzde bir tane teknik ya da müdahale değil; çocuğun ve ailenin ihtiyaçlarına göre oluşturulan "bireysel biçimlendirilmiş" bakım sistemleri ön plandadır. Bu sistemde çocuğun fonksiyonel durumuna göre yapılandırılması gereken, hedeflenen aktivite ve katılım kazanımlarına yönelik terapi-uygulamateknik-yöntem-araç-gereç-cerrahi-ilaç-spor ve rekreasyonel aktiviteler-eğitim müdahaleleri-psikolojik ve sosyal destek seçilerek ve çoğunlukla da birleştirilerek kullanılmaktadır. Bu da, bütüncül değerlendirme konusunda bilgili ekip elemanlarını gerektirmektedir.

Diğer önemli bir durum, çocukların gençlik ve yetişkinlik dönemlerinde SP tablosuna ikincil kas-iskelet sistemi sorunlarının eklenmesi ve daha kötüleşme riski altında olmalarıdır. Bağımsız ya da araç destekli yürüyebilen mobil SP'li gençlerde (12-18 yaş), bu tür ikincil sorunlar sıklıkla fonksiyon azalmasına katkıda bulunmaktadır. Bunun sonucunda, günlük yaşam aktivitelerinde, topluma katılımda, sosyal etkileşimlerde ve fizyolojik refah durumunda bağımsızlık azalmaktadır. íkincil kas-iskelet sistemine ait sorunların ortaya çıkması ve doğasının değişmesi, günümüzde SP ile ilgili ifade edilen; beyin lezyonunun kendisinin statik ve ilerleyici olmadığı, ancak tipik olarak ilerleyici ikincil kas-iskelet 
sistemi sorunlarının eşlik ettiği bir klinik tablo olduğu gerçeğini yansıtır. Bu nedenle, SP'nin fonksiyonel etkisi yaşam süresi boyunca değişebilir ve dinamik olabilir. Dolayısıyla, ikincil sağlık sorunlarını sınırlandıran veya önleyen müdahalelerin geliştirilmesi ve değerlendirilmesi için kanıta dayalı bilgilerin elde edilmesine acilen ihtiyaç duyulmaktadır. En sık bildirilen kas-iskelet sistemi sorunları; ağrı, osteoartrit, yorgunluk ve fiziksel aktivite azalmasıdır. ${ }^{[33-34]}$

SP'li çocuklarda bakım ve rehabilitasyon uygulamalarını yürüten ekip üyeleri, çocukların evlerinde ve toplum içinde bağımsız ve yeterli potansiyele ulaşmalarında yardımcı olmaya çalışırlar. Rehabilitasyonun etkisi sağlık merkezi ve jimnastik odasıyla sınırlı olmamalı; çocukların evde, okulda, sosyal ortamlarında ve topluluk içindeki fonksiyonel yaşamlarına da yönelik olmalıdır. Tıbbi ve cerrahi uygulamalar dışındaki rehabilitasyon uygulamaları içinde, fizyoterapi ve rehabilitasyon uygulamaları, ergoterapi, ortez uygulamaları, dil ve konuşma terapisi, odyolojik yaklaşım ve destekler, özel eğitim, çocuk gelişimi ve pedagojik yaklaşım ile birlikte aile ve çocuk için psiko-sosyal destek, spor ve rekreasyonel aktiviteler önem kazanmaktadır.

Sonuç olarak; hangi yaşta olursa olsun SP'li çocukların bakımları için etkili hizmetlerin geliştirilmesi, bu popülasyonun yaşam süresi boyunca yaşaması muhtemel sağlık sorunları hakkında ayrıntılı bilgiye, tavsiyede bulunurken ve yönetimde temel alınabilecek sağlam kanıtlara sahip olunması gerekmektedir. Cerebral Palsy International Research Foundation (Uluslararası Serebral Palsi Araştırma Vakfı), sadece yeni bir sağlık bakım ortamından ziyade, engelli bireylerin yaşam boyu fonksiyonlarının en üst düzeye çıkarılması için bir sağlık hizmetleri sistemine geçilmesi konusunda ısrar etmiştir. $\mathrm{Bu}$ plan, çocukların toplumdaki sosyal ve ekonomik hayata katılmaları için fırsatların arttırılmasını amaçlamaktadır. Ailelerin optimum düzeyde bağımsız fonksiyon ve katılım için ekipman satın alabildikleri ve ihtiyaç duydukları terapiye ulaşabilmek için kendi finansman paketlerini kullanma yetkisine sahip oldukları; sağlık sorunlarına ve ihtiyaçlarına cevap veren bir sağlık hizmetleri sistemi gerekmektedir. Ancak, engelli geçen yaşam süresinde kesintisiz rehabilitasyon hizmetinin sağlanması için, sağlık profesyonellerinin acil olarak becerilerini arttırmaları ve herhangi bir yaşta fonksiyon ve mobilite azalması yaşayan SP'li çocuklara kanıta dayalı tıbbi müdahaleler sunabilmek için eğitim almaları gerekmektedir. Ayrıca, SP'li yetişkinlerin, sağlık müdahaleleri hakkında tercihlerini yapmaları için bilgilendirilmeleri de gerekir. ${ }^{[35]}$

SP'li pek çok çocuk, yaşları ilerledikçe, mobilite azalması ve ikincil kas-iskelet sistemi sorunlarının ortaya çıkması ile güçlükler yaşar. Yürümede azalma ve düşmeler yaygındır; bunlar potansiyel olarak aktivite, katılım ve sağlıkla ilgili yaşam kalitesini etkiler. Mobilite azalmasının prevalans ve etkilerinin değerlendirilmesi ve karakterize edilmesi için, dikkatle yapılandırılmış, popülasyona dayalı örneklemlerde kesitsel çalışmaların yapılması gerekmektedir. Klinik uygulamayı yönlendirecek kanıtlar günümüzde oldukça azdır. Çocuklarda kapsamlı ve fonksiyonel bir değerlendirme sonrası yapılandırılan bakım uygulamaları ve bu doğrultuda aile eğitimi, ailenin desteklenmesi, çocuğun yaşamını kolaylaştırır. Sağlık profesyonelleri tarafından pediatrik rehabilitasyon alanındaki yeniliklerin takibi ve tatbiki büyük önem taşır. "Çocuklar büyüklerin minyatürü değildir ve çocuğa uygulanacak her doğru yaklaşım geleceğini şekillendirir".

\section{KAYNAKLAR}

1. Rosenbaum $P$, Paneth $N$, Leviton $A$, Goldstein $M$, Bax $M$, Damiano D, Dan B, Jacobsson B. A report: the definition and classification of cerebral palsy April 2006. Dev Med Child Neurol Suppl 2007;109:8-14.

2. Serdaroğlu A, Cansu A, Ozkan S, Tezcan S. Prevalence of cerebral palsy in Turkish children between the ages of 2 and 16 years. Dev Med Child Neurol 2006;48(6):413-6. Crossref

3. Trabacca A, Vespino T, Di Liddo A, Russo L. Multidisciplinary rehabilitation for patients with cerebral palsy: improving longterm care. J Multidiscip Healthc 2016;22;9:455-62. Crossref

4. Himmelmann K, Uvebrant P. Function and neuroimaging in cerebral palsy: a population-based study. Dev Med Child Neurol 2011;53(6):516-21. Crossref

5. Nieuwenhuijsen C, Donkervoort M, Nieuwstraten W, Stam $\mathrm{HJ}$, Roebroeck ME. Experienced problems of young adults with cerebral palsy: targets for rehabilitation care. Arch Phys Med Rehabil 2009;90(11):1891-7. Crossref

6. Andersson C, Mattsson E. Adults with cerebral palsy: a survey describing problems, needs, and resources, with special emphasis on locomotion. Dev Med Child Neurol 2001;43(2):76-82. Crossref

7. Gabis LV, Tsubary NM, Leon O, Ashkenasi A, Shefer S. Assessment of abilities and comorbidities in children with cerebral palsy. J Child Neurol 2015;30(12):1640-5. Crossref

8. Kerem Günel M. Rehabilitation of children with cerebral palsy from a physiotherapist's perspective. Acta Orthop Traumatol Turc 2009;43(2):173-80. Crossref

9. Schiariti V, Klassen AF, Cieza A, Sauve K, O'Donnell $M$, Armstrong R, Mâsse LC. Comparing contents of outcome measures in cerebral palsy using the International Classification of Functioning (ICF-CY): a systematic review. Eur J Pediatr Neurol 2014;18(1):1-12. Crossref

10. Cans C. Surveillance of cerebral palsy in Europe: a collaboration of cerebral palsy surveys and registers. Surveillance of Cerebral Palsy in Europe (SCPE). Dev Med Child Neurol 2000;42(12):816-24. Crossref

11. Palisano RJ, Rosenbaum $\mathrm{P}$, Bartlett $\mathrm{D}$, Livingston $\mathrm{MH}$. Content validity of the expanded and revised Gross Motor Function Classification System. Dev Med Child Neurol 2008;50(10):744-50. Crossref

12. Eliasson A-C, Krumlinde-Sundholm L, Rösblad B, Beckung E, Arner M, Öhrvall A-M, Rosenbaum P. The Manual Ability Classification System (MACS) for children with cerebral palsy: scale development and evidence of validity and reliability. Dev Med Child Neurol 2006;48(7):549-54. Crossref 
13. Hidecker MJC, Paneth N, Rosenbaum PL, Kent RD, Lillie J, Eulenberg JB, Chester K Jr, Johnson B, Michalsen L, Evatt M, Taylor K. Developing and validating the Communication Function Classification System for individuals with cerebral palsy. Dev Med Child Neurol 2011;53(8):704-10. Crossref

14. Sellers D, Mandy A, Pennington L, Hankins M, Morris C. Development and reliability of a system to classify the eating and drinking ability of people with cerebral palsy. Dev Med Child Neurol 2014;56(3):245-51. Crossref

15. Kerem Günel M, Türker D, Özal C, Kaya Kara O. Physical Management of Children with Cerebral Palsy. In: Švraka E, editor. Cerebral Palsy -Challenges for the Future. Intech; 2014. p.29-72. Crossref

16. Kerem Günel M. Physiotherapy for Children with Cerebral Palsy. In: Gadže ZP, editor. Epilepsy in Children - Clinical and Social Aspects.London, UK: Intech; 2011. pp. 213-34. Crossref

17. Kerem Günel M, Türker D, Özal C, Kara ÖK. Fizyoterapi ve Rehabilitasyon Uygulamaları Özelinde; Fizyoterapist Gözüyle Serebral Palsi. Klinik Tıp Pediatr Derg 2014;3.

18. Graham HK, Rosenbaum P, Paneth N, Dan B, Lin JP, Damiano DL, Becher JG, Gaebler-Spira D, Colver A, Reddihough DS, Crompton KE, Lieber RL. Cerebral palsy. Nat Rev Dis Primers 2016;2:15082. Crossref

19. Öksüz Ç, Alemdaroglu I, Kilinç $M$, Abaoğlu H, Demirci C, Karahan S, Yilmaz O, Yildirim SA. Reliability and validity of the Turkish version of ABILHAND-Kids' questionnaire in a group of patients with neuromuscular disorders. Physiother Theory Pract 2017;33(10):780-7. Crossref

20. Sköld A, Hermansson LN, Krumlinde-Sundholm L, Eliasson AC. Development and evidence of validity for the Children's Hand-use Experience Questionnaire (CHEQ). Dev Med Child Neurol 2011;53(5):436-42. Crossref

21. Batcho CS, Tennant A, Thonnard J-L. ACTIVLIM-Stroke: a crosscultural Rasch-built scale of activity limitations in patients with stroke. Stroke 2012;43(3):815-23. Crossref

22. Park ES, Joo J-W, Kim SA, Rha D-W, Jung SJ. Reliability and Validity of the Upper Limb Physician's Rating Scale in Children with Cerebral Palsy. Yonsei Med J 2015;56(1):2716. Crossref

23. Thorley M, Lannin N, Cusick A, Novak I, Boyd R. Construct validity of the Quality of Upper Extremity Skills Test for children with cerebral palsy. Dev Med Child Neurol 2012;54(11):1037-43. Crossref

24. Msall ME, DiGaudio K, Rogers BT, LaForest S, Catanzaro NL, Campbell J, Wilczenski F, Duffy LC. The Functional Independence Measure for Children (WeeFIM) -conceptual basis and pilot use in children with developmental disabilities. Clin Pediatr 1994;33(7):421-30. Crossref
25. Kerem Günel M. Prematüre Bebekte Erken Fizyoterapi. Katkı Pediatri Dergisi 2005;5:485-91.

26. Spittle AJ, Doyle LW, Boyd RN. A Systematic Review of The Clinimetric Properties of Neuromotor Assessment for Preterm Infants During the First Year of Life. Dev Med Child Neurol 2008;50(4):254-266. Crossref

27. Novak I, Mcintyre S, Morgan C, Campbell L, Dark L, Morton $\mathrm{N}$, Stumbles E, Wilson SA, Goldsmith S. A systematic review of interventions for children with cerebral palsy: state of the evidence. Dev Med Child Neurol 2013;55(10):885-910. Crossref

28. Katz-Leurer M, Rotem $\mathrm{H}$, Keren O, Meyer S. The effects of a 'home-based' task-oriented exercise programme on motor and balance performance in children with spastic cerebral palsy and severe traumatic brain injury. Clin Rehabil 2009;23(8):714-24. Crossref

29. Rigby BR, Gloeckner AR, Sessums S, Lanning BA, Grandjean PW. Changes in Cardiorespiratory Responses and Kinematics With Hippotherapy in Youth With and Without Cerebral Palsy. Res Q Exerc Sport 2017;88(1):26-35. Crossref

30. Morris C. A review of the efficacy of lower-limb orthoses used for cerebral palsy. Dev Med Child Neurol 2002;44(3):20511. Crossref

31. Tervahauta M, Girolami G, Øberg G. Efficacy of constraintinduced movement therapy compared with bimanual intensive training in children with unilateral cerebral palsy: a systematic review. Clin Rehabil 2017;31(11):1445-56. Crossref

32. Klepper SE, Krasinski DC, Gilb MC, Khalil N. Comparing Unimanual and Bimanual Training in Upper Extremity Function in Children With Unilateral Cerebral Palsy. Pediatr Phys Ther 2017;29(4):288-306. Crossref

33. Novak I. Evidence-based diagnosis, health care, and rehabilitation for children with cerebral palsy. J Child Neurol 2014;29(8):1141-56. Crossref

34. Franki I, Desloovere K, De Cat J, Feys H, Molenaers G, Calders $P$, Vanderstraeten G, Himpens E, Van Broeck C. The evidencebase for basic physical therapy techniques targeting lower limb function in children withcerebral palsy: a systematic review using the International Classification of Functioning, Disability and Health as a conceptual framework. J Rehabil Med 2012;44(5):385-95. Crossref

35. Maitre NL, Marshall DD, Price WA, Slaughter JC, O'Shea TM, Maxfield C, Goldstein RF. Neurodevelopmental outcome of infants with unilateral or bilateral periventricular hemorrhagic infarction. Pediatrics 2009;124(6):e1153-60. Crossref 